\title{
A conceptual framework to promote career development for vocational rehabilitation consumers with traumatic brain injuries
}

\author{
David R. Strauser ${ }^{\mathrm{a}, *}$, Phillip D. Rumrill ${ }^{\mathrm{b}}$ and Chelsea Greco ${ }^{\mathrm{a}}$ \\ ${ }^{\mathrm{a}}$ University of Illinois at Urbana-Champaign, Champaign, IL, USA \\ ${ }^{\mathrm{b}}$ Kent State University, Kent, OH, USA
}

Received 2 March 2019

Accepted 23 July 2019

\begin{abstract}
The purpose of this article is to describe the Illinois Work and Well-being Model (ILW ${ }^{2} \mathrm{M}$ ), a multi-domain framework for conceptualizing the employment development of people with traumatic brain injuries (TBIs). The model emphasizes the interaction of contextual and career development domains to improve participation in the areas of work, society, community, and home. A brief discussion of potential implications regarding vocational rehabilitation research and service is offered with the overall goal of reinforcing employment development as the foundation of vocational rehabilitation services for adults with TBIs.
\end{abstract}

Keywords: Traumatic brain injury, career development, well-being, employment

\section{Introduction}

Engaging in meaningful and productive workrelated activities is fundamental to the physical health, psychological well-being, and quality of life of people with and without disabilities, including people with traumatic brain injuries (TBIs) [1]. Research suggests that meaningful paid work activity is a critically important factor in providing avenues for economic security and access to health insurance and in facilitating social participation as well as improving health and quality of life [2]. Work is considered a fundamental human right of people with disabilities and the primary focus of vocational rehabilitation

*Address for correspondence: David R. Strauser, Ph.D., University of Illinois at Urbana-Champaign, Work and Disability Lab, 213A Huff Hall, MC-588, 1206 South Fourth Street, Champaign, IL 61820, USA. Tel.: +1 901481 6868; E-mail: strauser@illinois.edu. services [3]. Therefore, using scientifically validated interventions based on theoretical models and frameworks to enhance employment has been an important focus of governmental policy and programs. Despite this focus, there is a significant disparity in the access of vocational rehabilitation services, level of employment, and labor market participation for individuals with chronic health conditions and disability.

\section{Traumatic brain injury}

Vocational rehabilitation researchers have accorded increasing attention in recent years to the growing population of people with TBIs. The World Health Organization (WHO) [4] considers TBI a global public health crisis. TBI is attributed to approximately half of all trauma-related deaths worldwide, and it is the leading cause of death and 
lifelong disability among Americans under the age of 45 [5]. As many as 2.3 million Americans sustain TBIs each year, and more than 500,000 of these individuals never receive treatment for their injuries [5]. In 2014, the CDC estimated that 5.3 million Americans were living with the effects of TBI.

The Shepherd Center [6] reported the four most common causes of TBI in the U.S. as motor vehicle accidents, falls, violence and/or gunshot wounds, and military attacks or bomb blasts. Recent years have seen particularly sharp increases in the incidence of TBI among children, young adults, and American military personnel [7,8]. The CDC [9] reported a 57 percent increase in TBIs related to sports and recreational activities among people under the age of 19 during the first decade of the 21 st Century. The Defense and Veterans Brain Injury Center [10] reported that more than 370,000 United States military service members have received first-time diagnoses of TBI since 2000. From a developmental perspective, younger people are especially vulnerable to combat-related TBIs; more than two-thirds of American military personnel who have sustained TBIs during the Iraq and Afghanistan campaigns were under the age of 30 at the time of their injuries [11].

The physical, sensory, cognitive, and psychological effects of TBI on civilians and military personnel are well documented [12]. Falvo [13] described common physical symptoms of TBI including fine and gross motor disturbances, spasticity, tremors, diminished strength and stamina, fatigue, sexual dysfunction, chronic pain, and speech dysfluencies. She also described sensory symptoms such as visual and perceptual impairments and hearing loss. Frain et al. [14] noted that TBI is often characterized by cognitive impairments in such areas as short, intermediate, and long-term memory; attention control and task adherence; executive function; social cognition; analytical abilities; and information retrieval. Frain et al. [14] and Dillahunt-Aspillaga et al. [15] also noted that people who experience TBIs have elevated risks for depression, anxiety disorders, post-traumatic stress disorder (PTSD), suicidal ideations, and substance use disorders. They are also likely to experience emotional lability, low frustration tolerance, irritability and impatience, hyper-sexuality (especially males), disinhibited speech and behavior, and feelings of persecution and isolation $[13,15]$.

For the growing numbers of young people with TBIs, the preceding effects occur during critically important developmental periods when they are attempting to acquire training and make initial career choices [16]. Indeed, Wehman, Chen, West, and Cifu [17] reported that only 51 percent of young adults with TBI were employed in paying jobs. For veterans with TBI, these complications arise when they need to refresh their employment skills and re-enter civilian life. In fact, Dillahunt-Aspillaga et al. [15] reported that employment-related issues were the number one concern for military personnel who had recently acquired TBIs.

Employment outcomes for individuals with TBI lag far behind those of the general population. Whether the brain injury is mild or more severe, many obstacles related to the physical, emotional, and cognitive symptoms of TBI prevent people from successfully finding and keeping jobs. Looking for job leads, keeping track of appointments, and going on interviews are frequently overwhelming [16]. Once on the job, adapting to change and interacting with co-workers may become problematic. Forgetting a deadline, incorrectly processing a customer's order, or misinterpreting a supervisor's directive may affect the person's performance and job satisfaction [18]. It has been reported that $75 \%$ of individuals with TBI who return to work lose their jobs within 90 days if they do not have adequate job retention supports such as assistive technology and other reasonable accommodations [19].

Even after an individual with a TBI is successfully employed, he or she may subsequently need help when adapting to changes in job or life situations [20]. Frain and colleagues [14] cited the loss of social supports that often accompanies TBI, changes in one's cognitive abilities as a result of injury, and employers' lack of understanding of how to accommodate workers with TBI as three major reasons for the difficulties that civilians and military personnel with TBI have in maintaining their careers post-injury. They estimated the rate of labor force participation among workingage Americans with moderate and severe TBIs to be less than 40 percent.

In particular, cognitive impairments related to short-term memory, long-term memory, information processing, executive functioning, and social judgment have been identified as prominent employment barriers for civilians [21] and veterans [15] with TBI. Roessler et al. [22] presented findings from qualitative case studies of employed college graduates with TBIs indicating significant barriers related to essential job functions such as remembering appointments, multi-tasking, communicating with co-workers and supervisors, maintaining electronic 
and written correspondence with clients and customers, and learning new tasks. Participants also reported a general lack of awareness of (a) strategies for compensating for cognition-related employment barriers and (b) resources that could assist them in implementing needed on-the-job supports (e.g., the Job Accommodation Network, the National Americans with Disabilities Act Centers Network, the Virginia Commonwealth University Rehabilitation Research and Training Center on Workplace Supports; [3, 23]). Further exacerbating the impact of cognitive impairments on labor force participation for people with TBI is the fact that workplace accommodations to address cognitive limitations are among the most difficult modifications to implement for people with disabilities according to Scherer [24] and the Job Accommodation Network [25]. Catalano et al. [21] reported national-level data from the Rehabilitation Services Administration indicating that the lack of access to assistive technology, especially technology to compensate for cognitive limitations, is a major reason for the significant problems of unemployment and underemployment among Americans with TBI.

The state-Federal vocational rehabilitation (VR) program is the nation's oldest and largest provider of employment services for Americans with disabilities [3]. The VR program spends more than $\$ 2.5$ billion per year for services ranging from assessment, diagnosis, medical services, and counseling to training, job placement, and job retention services [26]. Unfortunately, individuals with TBI tend to underutilize VR services; only one-third of Americans with TBI have ever heard of the state-Federal VR program, and only five to six percent receive state VR services [27, 28]. Typically, VR services for people with TBIs are provided only to individuals with moderate to severe injuries, which leaves many people with less severe injuries without options for vocational services and employment supports. Among service-eligible individuals with TBI who do avail themselves of state VR services, less than half (49\%) are successfully rehabilitated in competitive labor market employment [23]. This success rate falls below those experienced by VR consumers with most other disabling conditions [3].

\section{The centrality of work to health and well-being for people with TBI}

Because work is closely tied to meeting basic needs and increased physical and psychological well-being, and because it is an expected outcome of the vocational rehabilitation process, gaining an understanding of the components that impact an individual's career development is not only important for vocational rehabilitation, but also has important physical and psychological health implications. Career development describes a complex, multifaceted, lifelong process of an individual's efforts to develop and maintain connection with productive activities such as education, paid work, and providing care to important family members and others of significance [29]. It encompasses both structural and long-term changes in behavior [30] and is directly applicable to young people, including those who experience chronic health conditions and disabilities [31].

More specifically, career development can be conceptualized as an interaction of individual behavioral, affective, and cognitive processes that are influenced by contextual variables (family, socioeconomic status [SES], gender) and consists of the following three phases: 1) awareness (making sure the environment fits with the individual's values, skills, etc.), 2) acquisition (job seeking and placement), and 3) maintenance (what it takes to keep a job) [31-34]. Researchers have found that due to chronic health conditions or disability related factors, individuals may not have had the opportunity to develop the skills, or have had the necessary experiences, to develop effective employment-related behaviors and may have difficulty finding employment consistent with their residual functional capacity [35]. Such is often the case for people with TBIs, especially for the growing numbers of young people whose TBIs result in interruptions of schooling, a heightened sense of health vulnerability, and greater risks for educational and occupational difficulties over the long term [36]. In terms of occupational outcomes, adults with disabilities and chronic health conditions such as TBI are more likely to report more performance limitations, difficulty attending work [37], lower income [37], and lower likelihood of working during high school than their peers [38]. Young people with disabilities also express greater uncertainty regarding plans for occupational advancement [39].

Because employment is a developmental process that is affected by a variety of individual and systemic factors, it is important to have an operational framework for conceptualizing the employment development process. In this article, we provide a brief overview of the Illinois Work and Well-Being Model $\left(\mathrm{IW}^{2} \mathrm{M}\right)$ and discuss how it can be applied to promote the career development and employment of 


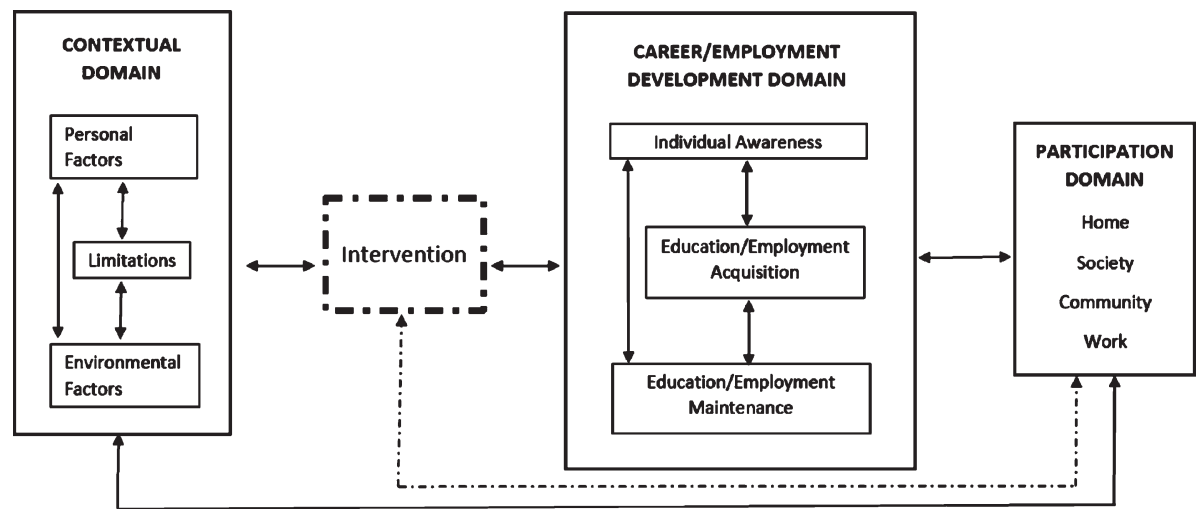

Fig. 1. Illinois Work and Well-Being Model.

people with TBI. The $\mathrm{IW}^{2} \mathrm{M}$ is designed to be parsimonious in nature to facilitate broad application, yet refined enough to promote in-depth research related to each of the domains and factors making up the framework. After a description of the $\mathrm{IW}^{2} \mathrm{M}$ there will be a discussion of the IW $^{2} \mathrm{M}$ 's implications for service and research regarding people with TBI.

\section{Illinois Work and Well-Being Model}

The IW ${ }^{2}$ M (Fig. 1) identifies the interaction of contextual, employment development, and participation domains as key elements in explaining how personal, environmental, TBI and treatment related, educational, and potential interventions serve as facilitators or barriers related to overall societal participation. The framework is grounded in the major tenets of the World Health Organization's International Classification of Health, Function, and Disability (ICF; 2001) framework and theory-driven research related to the career development and employment of individuals with disabilities such as TBI.

The ICF model is an integration of four major concepts including: body functions and structures, activities and participation, environmental factors, and personal factors. All of these factors relate to understanding an individual's overall level of functioning and consider the impact of medical and social aspects of disability and chronic health conditions on participation [40]. The activities and participation section discusses nine different domains of involvement in life situations and roles, one of which mentions employment. The $\mathrm{IW}^{2} \mathrm{M}$ builds upon this understanding by still emphasizing the importance of considering biological, personal, and contextual factors of each individual but expands upon participation by separating out and expanding upon the career development and employment. The various individual factors (Individual Awareness, Education/Employment Acquisition, and Education/Employment Maintenance) reflect theory-driven research surrounding career development [41-45].

The framework has three major domains (Contextual, Career Development, and Participation) with an intervention component that facilitates the interaction between the contextual and career development domains and conceptually has a direct and indirect effect on the participation domain. The type and focus of interventions are not specified, and no theoretical orientation is preferred over another. Conceptually, the three domains and the intervention component of the framework provide a structure to operationalize how career development and employment are related to overall participation of individuals with TBI.

The $\mathrm{IW}^{2} \mathrm{M}$ is not designed to replace specific theories that attempt to explain or describe important career and employment constructs such as decision-making; motivation; and interest, value, or personality development. Instead, in applying the $\mathrm{IW}^{2} \mathrm{M}$, those constructs and theories are viewed as important process-oriented factors that are inherent and embedded in the framework. In addition, like the framework's domains and factors, these process factors should be points of relevant and valuable career development and employment research.

\section{Illinois Work and Well-Being domains}

The IW ${ }^{2} \mathrm{M}$ consists of Contextual, Career Development and Participation domains that interact to 
Table 1

Domains, factors and components of the Illinois Work and Well-Being Model

\begin{tabular}{|c|c|c|}
\hline Domain & Factors & Components \\
\hline \multirow[t]{6}{*}{ Contextual } & Personal & $\begin{array}{l}\text { personality, interests, values, gender, age, ethnicity, } \\
\text { aptitude, SES, education attainment, identity, past personal } \\
\text { experiences, temperament }\end{array}$ \\
\hline & $\begin{array}{l}\text { Environmental } \\
\text { - Individual level: individual systems of sup- } \\
\text { port; support network } \\
\text { - Services level: services and resources avail- } \\
\text { able } \\
\text { - Cultural/legal systems levels: societal and } \\
\text { cultural attitudes; political and legal factors } \\
\text { (Falvo, 2014; Peterson \& Rosenthal, 2005) }\end{array}$ & $\begin{array}{l}\text { culture, society, economic physical environment, quality of } \\
\text { education, discrimination, services available, political } \\
\text { systems, transportation, technology, climate, social } \\
\text { attitudes, }\end{array}$ \\
\hline & Functional/Limitations & Physical \\
\hline & - Capacity: actual ability & Communication (expression \& reception) \\
\hline & - Maximum function-greatest degree of & $\begin{array}{l}\text { Emotional } \\
\text { Cognitive, Executive functioning }\end{array}$ \\
\hline & $\begin{array}{l}\text { - Performance: actually does } \\
\text { - Optimal functioning-subjective view- } \\
\text { point of the individual and derived from } \\
\text { individual goals and experience }\end{array}$ & \\
\hline \multirow[t]{3}{*}{ Career } & Awareness & $\begin{array}{l}\text { Vocational identity, career awareness, vocational maturity, } \\
\text { work personality }\end{array}$ \\
\hline & Acquisition & $\begin{array}{l}\text { Job seeking skills, impression management, Resume } \\
\text { Development }\end{array}$ \\
\hline & Maintenance & $\begin{array}{l}\text { Carry out required job tasks, meet production demands, } \\
\text { complete normal work day, Engage co-workers }\end{array}$ \\
\hline \multirow[t]{4}{*}{$\overline{\text { Participation }}$} & Home & $\begin{array}{l}\text { Independent living, Self-care at home (bath, cook) Maintain } \\
\text { house (clean), Wash cloths, choose or create contexts } \\
\text { suitable to meet personal needs and values, manage every } \\
\text { day affairs }\end{array}$ \\
\hline & Society/Social & $\begin{array}{l}\text { Appropriate social relationships, meaningful and trusting } \\
\text { intimate relationships, understands give and take of human } \\
\text { relationships, }\end{array}$ \\
\hline & Community & $\begin{array}{l}\text { Concerned about the welfare of others, engages in } \\
\text { appropriate community activities, Access and use } \\
\text { appropriate transportation, engage in appropriate civic } \\
\text { activities }\end{array}$ \\
\hline & Work & $\begin{array}{l}\text { Maintain steady employment, meet the demands of work, } \\
\text { engage in career development, earn appropriate wages }\end{array}$ \\
\hline
\end{tabular}

provide a structure for understanding the career and employment development of people with TBIs. The Career Interventions component is purposefully situated between the Contextual and Career Development domains. As a result, the model implies that career interventions directly and indirectly influence both the Contextual and Career Development domains and have an indirect effect on the Participation domain. Each domain is comprised of factors, which allows for analysis at both the individual domain and factor levels. As a result, domains and factors can be conceptualized as both independent and interdependent in nature. All arrows between domains and factors are bi-directional, indicating a reciprocal effect between the model's components.
Relationships between domains, factors, and interventions can be positive, negative, or neutral, implying that the value of the directional impact is determined by the situation-specific activities, expressions, and reactions to both specific and broad stimuli. Each domain is briefly described below and outlined in Table 1. A detailed discussion regarding the $\mathrm{IW}^{2} \mathrm{M}$ can be found in Strauser, Greco, and O'Sullivan [45] and Strauser, O'Sullivan, and Wong [46].

The Contextual domain applies the ICF framework as a guide to operationalize how personal and environmental factors interact with TBI and treatment-related limitations and restrictions. The bidirectional arrows between the domain factors imply 
a reciprocal relationship whereby growth or change in one factor can directly or indirectly impact the growth or change in the other factors. The solid bidirectional arrow between the Contextual and Career Development domains indicates a direct reciprocal connection between these two major domains independent of any intervention, implying a mutually interdependent developmental process. The solid bidirectional arrow along the bottom of the model between the Contextual and Participation domains implies a reciprocal relationship independent of the Career Development domain and any career interventions.

The Career Development domain is based on career and employment research related to individuals with disabilities. The domain consists of the following three factors: Individual Awareness, Educational and Employment Acquisition, and Educational and Employment Maintenance. Specifically, Awareness is developmentally mediated with the individual becoming aware of how he or she relates to the world and in which activities he or she may choose to participate. The individual awareness factor theoretically provides the foundation for the acquisition and maintenance factors, although, as implied by the bi-directional arrows, all factors have a reciprocal impact influencing each factors continual development. The Education and Employment Acquisition factor addresses the process by which individuals go about acquiring access to educational and employment related activities. From an educational perspective, acquisition includes, but is not limited to, the process and activities associated with applying for appropriate educationally related activities including trade, two-year, and four year training programs. The Employment and Educational Acquisition factor provides the foundation for the Maintenance Factor related activities and has a reciprocal impact on individual awareness. The Educational and Employment Maintenance factor addresses the activities and behaviors associated with maintaining engagement and participation in educational and occupationally related activities. Although Maintenance occurs after Acquisition and is typically conceptualized as an outcome, it too has a reciprocal effect on the preceding factors. For example, maintaining employment strengthens an individual's vocational identity which increases and solidifies career awareness. Additionally, maintenance also has a direct effect on Acquisition through increased experiences and knowledge of the labor market that allow for potential future educational and employ- ment opportunities that are more consistent with their identity.

The Participation Domain utilizes the ICF framework as a guide to identify meaningful and broad-based participation in major life areas. In this conceptual model the life areas of home, society, community, and work have been identified and can serve as outcomes of interest. Although the work area may seem an obvious focal area for those working to improve career development and employment outcomes for individuals with TBIs, the model stresses the interconnectivity of all participation areas. A fundamental tenet guiding the model is that increased positive participation will lead to an overall increase an individual's well-being and overall quality of life.

According to the conceptual model, the Intervention Component is situated between the Contextual and Career Development Domains. This placement suggests that the primary goal of career preparatory, educational, and employment interventions is to facilitate and maximize the direct interaction between the Contextual and Career domains, which will, in turn, indirectly impact the Participation Domain. By pulling the intervention component outside of the Career Development Domain and placing it between the Contextual and Career Development Domains, the model implies that interventions should focus on the correspondence between the two respective domains. Effective interventions should focus on maximizing the personal, environmental, and TBI related limitations to impact the Career Development Domain and specific Career Development Domain factors.

\section{Implications for career development and employment participation of people with TBI}

There are a number of implications involved in applying this model to increase the career development and employment participation of people with TBI. One of the primary motives regarding the development of the $\mathrm{IW}^{2} \mathrm{M}$ was to guide researchers in examining the domains, factors, and participation outcomes related to career development and employment of individuals with TBI. One of the key components of the $\mathrm{IW}^{2} \mathrm{M}$ is that it allows researchers a framework to conduct both within-and across-domain analyses and examination at the factorial level. Practitioners can also apply the model to operationalize the factors and domains that may 
be contributing to decreased career development and labor market participation of individuals with TBI. Applying the $\mathrm{IW}^{2} \mathrm{M}$, practitioners can gain a more comprehensive conceptualization of service delivery resources and potential areas of need. In the following paragraphs, specific implications for service and research are briefly discussed.

\section{Case conceptualization and service}

The $\mathrm{IW}^{2} \mathrm{M}$ has implications for the delivery of vocational rehabilitation services for individuals with TBI at both the individual and program level. At the individual level practitioners can apply the model to conceptualize cases to identify specific needs and develop a service strategy that ensures that services are provided that address specific factors of need across and within domains. In applying the IW $^{2} \mathrm{M}$, practitioners can conduct a multilevel analysis of the individual through the identification of primary, secondary, and tertiary relationships and effects between and within factors and domains. Across domains, the model allows practitioners to identify the individual's personal, environmental, and functional contextual factors and examine if the factors are acting as facilitators or barriers regarding the various factors in the career development domain. Employing a multilevel analysis strategy, specific interventions and services can be directed to reduce the negative effect of specific contextual factors while leveraging the impact of other positive factors.

The multilevel analysis is also dynamic in nature, allowing for continual analysis both between domains and within factors as the individual's needs, facilitators, and barriers evolve and change in response to the impact of the specific services and interventions provided. For example, initial interventions, such as neuropsychological evaluation, may be used to help the individual gain a better understanding of his or her cognitive functioning and executive processing (Contextual Domain) to help promote increased vocational identity and awareness (Career Domain). Presuming that the neuropsychological evaluation is effective in helping the individual gain an increased understanding of his or her cognitive functioning and executive processing, which in turn increases vocational identity and awareness, the practitioner can build on the success to determine across domain and within domain impact and develop relevant clinical hypotheses and questions that will guide additional interventions, services, and supports. For example, in the Career Domain, does the individual's increased vocational identity and awareness allow the individual to develop an increased understanding and willingness to use neurocognitive accommodations and assistive technology to facilitate and increase job maintenance (Within Domain; [22, 24, 27])? Does increased clarity regarding the individual's cognitive and executive processing and increased career awareness increase the level of participation in social and community factors (Across Domains; [14])? Below we provide an example of how the $\mathrm{IW}^{2} \mathrm{M}$ can be used in a multilevel analysis to facilitate effective service delivery to individuals with TBI.

\subsection{Case example}

A 21-year-old male with a mild TBI is currently working part-time bagging groceries at a local grocery store. He likes his job, but he would like to pursue technical training in the computer field at a local community college. However, he has concerns regarding his ability to meet the demands of the program due to his decreased executive functioning and memory. In addition, he will need to maintain his employment at least part-time while attending the training program and is concerned that his post-injury fatigue will impact his ability to meet the demands of both his employment and school obligations. As a result of his multiple concerns, he is experiencing increased stress and increased self-doubt about whether he is really a fit for the training program and a more technical/professional career. His expressed concern about his decreased executive functioning, memory, and increased fatigue can be conceptualized as a primary across domain effect, with his perception of his decreased functioning (Contextual Domain) potentially impacting his ability to meet and maintain the required involvement in both his training program and employment (Career Domain). The impact of his across-domain concern regarding functioning and maintenance is contributing to a secondary withindomain effect; his concerns regarding his ability to meet the demands of both his job and training program (Job Maintenance) is creating doubts regarding his vocational identity (Awareness). Finally, because of his decreased vocational identity he is experiencing significant stress and anxiety, which causes him to further question personal factors such as his physical and emotional abilities, his individual and career values, and his ability to manage stress. Therefore, his decreased level of vocational identity is contributing to his decreased emotional functioning, which 
would be considered a tertiary across-domain effect (see Fig. 2).

Engaging in across and within domain level analysis may allow the practitioner to conceptualize the types of direct and indirect services and interventions that can be employed to maximize career and vocational outcomes. Using the example above, to address the primary impact of the individuals perceived functioning on job maintenance, the practitioner may choose to examine potential job modifications (modified work schedule) and strategies to enhance studying and managing future academic course work. Indirectly, the practitioner may recommend that the individual seek out and participate in appropriate health promotion activities offered through a local healthcare facility that will provide benefits to both his physical and mental health and overall well-being.

In addressing secondary and tertiary influences, the practitioner may choose to implement a combination of direct and indirect services. Directly, the practitioner may work with the individual to develop self-advocacy skills that allow the individual to engage the community college's Student Disability Services office to seek out appropriate academic accommodations to meet the demands of the educational environment. In addition, the practitioner may also provide direct service vocational counseling focused on helping the individual further explore how his interests and skills relate to his desire to pursue a specific vocational training program, which would strengthen his vocational identity. This measure would allow the individual to examine how the accommodations could be used to help him meet the demands of his current position, thereby preserving or

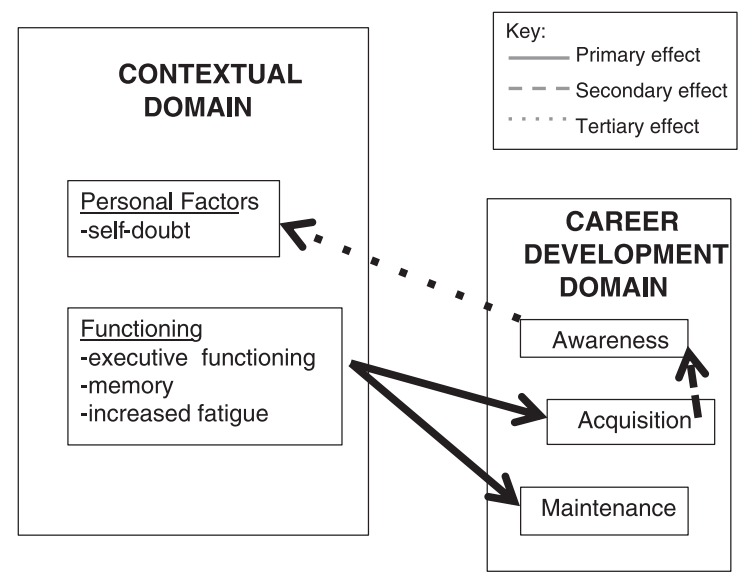

Fig. 2. Case Conceptualization with Primary, Secondary, and Tertiary effects. reinforcing his level of vocational identity. Indirectly, the practitioner may recommend that the individual seek personal adjustment counseling to help manage the stress and uncertainty regarding his ongoing TBI recovery. The practitioner may also recommend that the individual utilize a community fitness center to engage in regular exercise to help manage stress. The key to being successful is that practitioners use the model to leverage both direct and indirect services to provide a continuum of care across domains and levels (primary, secondary, tertiary) so that services become fully integrated and not fragmented.

\section{ILW $^{2} \mathrm{M}$ to facilitate program evaluation}

From an organizational perspective, the model can be applied to guide a multi-level and between and within domain program evaluation to identify potential areas of program strength and need. By applying the model in the program evaluation process, an organization serving individuals with TBI may find that the vocational services have been isolated to focus on one particular domain or factor, potentially limiting the services' reach and effectiveness. For example, an organization may primarily focus on job placement (acquisition) and have limited programming or services directed at developing awareness (i.e. vocational identity, career awareness). Therefore, implementing programming to strengthen awareness should contribute to better placement outcomes because research findings suggest that higher levels of awareness are associated with better employment outcomes [29].

Applying the model in the program evaluation process may also allow an organization to examine resource allocation and the potential need to shift or re-allocate resources to maximize program effectiveness. Program evaluation should also examine the depth and breadth of direct services offered and allow the agency to map indirect services to specific domains and factors to ensure comprehensive coverage of the individual's needs. Finally, application of the conceptual model at the agency level shifts and reinforces the view that the ultimate outcome of vocational rehabilitation service provision is an increase in all four participation domain factors.

\section{Research}

Given the unique and multifaceted career and employment needs of individuals with TBI there is a 
significant need to conduct research aimed at gaining an understanding of the factors impacting career and employment outcomes. Applying the ILW ${ }^{2} \mathrm{M}$ conceptual model to research has multiple implications for developing a comprehensive research strategy to address the career and employment needs of individuals with TBI. First, the model can be used to identify specific areas that are in need of research development. With a few exceptions (e.g. supported employment) career development research within the context of vocational rehabilitation has been limited in scope and has focused almost exclusively on issues related to the awareness factor, which may not be as applicable to the career and employment needs of adults with TBI. [29] By employing this conceptual model it becomes very clear that there are many other areas that need to be examined to gain a more complete understanding of the career and employment development process as it relates to adults with TBI. For example, to date very little, if any research, has taken an integrated approach to examine how the factors within the Career Development Domain interact with each other from a developmental perspective.

Second, the ILW ${ }^{2} \mathrm{M}$ conceptual model places an emphasis on broader societal participation as the overall goal of the career and employment development process, which is consistent with the ICF. The majority of the career and employment research completed within vocational rehabilitation has exclusively focused on the career development domain factors and constructs, such as career readiness or vocational identity [47], with minimal focus on the overall goal of how and why these factors and constructs relate to improving societal participation and overall well-being. Future research should focus on gaining an understanding of the interaction between the career and contextual domains that contribute to employment and participation and developing interventions that facilitate this process for individuals with TBI. (i.e., symptom management, memory aids, stress management, and cognitive retraining)

Third, by incorporating a contextual domain into the career development process, this model acknowledges and places an emphasis on addressing the chronic health factors as they relate to and impact the career development process. The acknowledgement of disability related factors has been emphasized in vocational rehabilitation research, but to date it has had limited application to empirical career development research. Addressing the interaction between medical and career-related factors is important and should be the foundation for career and employment development research with adults with disabling conditions such as TBI [48].

Fourth, this model expands the traditional focus of career development research from the withindomain to the across-domain level. This is an important expansion because it enlarges the scope of the research focus and places an emphasis on mfore complex questions related to the interactions among career development, chronic health, and treatment related factors. For example, the development of research questions that address the interaction between residual post-treatment health and functioning and the multiple factors within the career development domain would be important to address and require advanced analysis to examine the multilevel and mediator and moderator effects between factors and domains.

Finally, this model provides an impetus for conducting research focused on developing interventions that emphasize effective interaction among multiple domains and between domain factors and takes into account direct and indirect effects. For example, an intervention directed at job acquisition should not exclusively address factors within the career development domain, but should also take into account factors from the contextual domain such as personal, environmental, and functional limitations. In addition, by examining direct and indirect effects, researchers can conceptualize and analyze the primary, secondary, and tertiary impact of interventions and conduct analyses using mediator and moderator variables to gain a full understanding of an interventions impact on the individual's participation and overall physical and psychological well-being.

\section{Conclusion}

The intent of this article was to provide an overview of the IW $\mathrm{IW}^{2} \mathrm{M}$ and present it as a multi-domain conceptual model designed to guide career development and employment research and services for individuals with TBI. The model's domains and associated factors were explained, and participation in the areas of work, society, community, and home were conceptualized as outcomes of interest. Brief discussions of potential implications were presented at the service and research levels. It is the hope of the authors that the model will serve as a catalyst for broadening the scope and analysis of career and employment development services and research related to people with TBI. 


\section{Conflict of interest}

None to report.

\section{References}

[1] Dutta A, Gervey R, Chan F, Chou C-C, Ditchman N. Vocational rehabilitation services and employment outcomes for people with disabilities: A United States study. J Occup Rehabil [Internet]. 2008 Dec [cited 2019 Feb 27];18(4):32634. doi:10.1007/s10926-008-9154-z

[2] Bishop M, Chiu C-Y. Epilepsy and employment. In: Society, behavior and epilepsy. New York: Nova Science Publishers Inc.; 2011. p. 93-114.

[3] Rubin S, Roessler R, Rumrill P. Foundations of the vocational rehabilitation process. 7th ed. Austin: Pro-Ed; 2016.

[4] World Health Organization. Neurological disorders: public health challenges [Internet]. 2017. Available from: https:// www.who.int/mental_health/publications/neurological_ disorders_ph_challenges/en/.

[5] U. S. Department of Health and Human Services, Centers for Disease Control and Prevention, National Center for Injury Prevention and Control, Division of Unintentional Injury Prevention. Traumatic brain injury \& concussion [Analysis in brief on the Internet]. 2016 [cited 2019 Feb 27]. Available from: https://www.cdc.gov/ traumaticbraininjury/data/rates.html.

[6] Shepherd Center [Internet]. Atlanta: The Center; c2019. Commons causes for brain injury; 2018 [cited 2019 Feb 27]; [about 1 screen]. Available from: https://www. shepherd.org/patient-programs/brain-injury/about/causes.

[7] Dillahunt-Aspillaga C, Jorgensen Smith T, Hanson A, Ehlke S, Stergiou-Kita M, Dixon C, et al. Exploring vocational evaluation practices following traumatic brain injury. Behav Neurol. 2015;1-11.

[8] Faul M, Xu L, Wald MM, Coronado VG. Traumatic brain injury in the United States: emergency department visits, hospitalizations and deaths 2002-2006. Atlanta: Centers for Disease Control and Prevention (CDC) and National Center for Injury Prevention and Control. 2010 Mar. Available from: https://www.cdc.gov/ traumaticbraininjury/pdf/blue_book.pdf.

[9] Centers for Disease Control and Prevention. Nonfatal traumatic brain injuries related to sports and recreation activities among persons aged $\leq 19$ years-United States, 2001-2009. MMWR: Morbidity and Mortality Weekly Report. 2011;60(39):1337-1342.

[10] U. S. Department of Defense, Defense and Veterans Brain Injury Center. DoD worldwide numbers for TBI [Internet]. 2017. Available from: http://dvbic.dcoe.mil/dodworldwide-numbers-tbi.

[11] Wojcik BE, Stein CR, Bagg K, Humphrey RJ, Orosco J. Traumatic brain injury hospitalizations of US army soldiers deployed to Afghanistan and Iraq. Am J Prev Med. 2010 Jan 1;38(1):S108-16.

[12] Caplan B, Bogner J, Brenner L, McGarity S, Barnett SD, Lamberty G, Kretzmer T, Powell-Cope G, Patel N, NakaseRichardson R. Community reintegration problems among veterans and active duty service members with traumatic brain injury. J Head Trauma Rehabil. 2017 Jan 1;32(1): $34-45$.
[13] Falvo D, Holland BE. Medical and psychosocial aspects of chronic illness and disability. Jones \& Bartlett Learning; 2017 Mar 8.

[14] Hendricks DJ, Sampson E, Rumrill P, Leopold A, Elias E, Jacobs K, Nardone A, Scherer M, Stauffer C. Activities and interim outcomes of a multi-site development project to promote cognitive support technology use and employment success among postsecondary students with traumatic brain injuries. Neurorehabil. 2015 Jan 1;37(3): 449-58.

[15] Nakase-Richardson R, Stevens LF, Dillahunt-Aspillaga C, Hart T, Powell-Cope G, Dreer LE, Eapen BC, Barnett SD, Mellick D, Haskin A, Silva MA. Predictors of employment outcomes in veterans with traumatic brain injury: a VA traumatic brain injury model systems study. J Head Trauma Rehabil. 2017 Jul 1;32(4):271-282.

[16] Wehman P. Life Beyond the Classroom. 5th ed. Baltimore: Paul H. Brookes Publishing Co.; 2013.

[17] Wehman P, Chen CC, West M, Cifu G. Transition planning for youth with traumatic brain injury: Findings from the National Longitudinal Transition Survey-2. Neurorehabil. 2014 Jan 1;34(2):365-372.

[18] Stock S. Employment for persons with brain injuries in Oregon. Salem: Oregon Competitive Employment Project Oregon State Department of Human Services, Office of Vocational Rehabilitation Services. 2006 Dec.

[19] National Association of State Head Injury Administrators. Traumatic brain injury facts: vocational rehabilitation and employment services. Alabaster: The Association. 2006.

[20] Andrew J, Andrew MJ. Disability handbook. Linn Creek: Aspen Professional Services. 2017.

[21] Catalano D, Pereira AP, Wu MY, Ho H, Chan F. Service patterns related to successful employment outcomes of persons with traumatic brain injury in vocational rehabilitation. Neurorehabil. 2006 Jan 1;21(4):279-293.

[22] Roessler RT, Rumrill Jr PD, Rumrill SP, Minton DL, Hendricks DJ, Sampson E, Stauffer C, Scherer MJ, Nardone A, Leopold A, Jacobs K. Qualitative case studies of professional-level workers with traumatic brain injuries: A contextual approach to job accommodation and retention. Work. 2017 Jan 1;58(1):3-14.

[23] Wehman P. Transitional polytrauma rehabilitation: community competence, inclusion, and integration. Keynote Address presented at: the national VA polytrauma conference. 2017 May. Orlando, FL.

[24] Scherer MJ. Assistive technologies and other supports for people with brain impairment. Springer Publishing Company; 2011 Dec 20.

[25] Job Accommodation Network. Accommodation ideas for brain injury. 2017. Available from: https://askjan.org/media/brai.htm.

[26] Chiu CY, Chan F, Bishop M, da Silva Cardoso E, O'Neill J. State vocational rehabilitation services and employment in multiple sclerosis. Mult Scler J. 2013 Oct;19(12): 1655-64

[27] Rumrill P, Elias E, Hendricks DJ, Jacobs K, Leopold A, Nardone A, Sampson E, Scherer M, Stauffer C, McMahon BT. Promoting cognitive support technology use and employment success among postsecondary students with traumatic brain injuries. J Vocat Rehabil. 2016 Jan 1;45(1):53-61.

[28] Sykes-Horn W, Wrigley M, Wallace D, Yoels W. Factors associated with awareness of vocational rehabilitation services after traumatic brain injury. Arch Phys Med Rehabil. 1997 Dec 1;78(12):1327-30. 
[29] Strauser DR. Career development, employment, and disability in rehabilitation: From theory to practice. Springer Publishing Company; 2013 Sep 17.

[30] Herr EL, Cramer SH. Career guidance and counseling through the lifespan: systematic approaches. 4th ed. New York: Harper Collins. 1992.

[31] Strauser D, Klosky JL, Brinkman TM, Wong AW, Chan F, Lanctot J, Ojha RP, Robison LL, Hudson MM, Ness KK. Career readiness in adult survivors of childhood cancer: a report from the St. Jude Lifetime Cohort Study. J Cancer Surviv. 2015 Mar 1;9(1):20-9.

[32] Peterson GW, Sampson Jr JP, Reardon RC. Career development and services: A cognitive approach. Thomson Brooks/Cole Publishing Co; 1991.

[33] Sampson JP, Reardon RC, Peterson GW, Lenz JG. Career counseling and services: A cognitive information processing approach. Belmont: Thomson/Brooks/Cole; 2004.

[34] [34]Saunders DE, Peterson GW, Sampson JP, Reardon RC. (2000). Relation of depression and dysfunctional career thinking to career indecision. Journal of Vocational Behavior, 56, 288-298. doi:10.1006/jvbe.1999.1715

[35] Saunders DE, Peterson GW, Sampson Jr JP, Reardon RC. Relation of depression and dysfunctional career thinking to career indecision. J Vocat Behav. 2000 Apr 1;56(2):288-98.

[36] Turner CD, Rey-Casserly C, Liptak CC, Chordas C. Late effects of therapy for pediatric brain tumor survivors. J Child Neurol. 2009 Nov;24(11):1455-63.

[37] Dolgin MJ, Somer E, Buchvald E, Zaizov R. Quality of life in adult survivors of childhood cancer. Soc Work Health Care. 1999 Jul 1;28(4):31-43.

[38] Stam H, Grootenhuis MA, Last BF. The course of life of survivors of childhood cancer. Psycho-Oncology: J Psych Social Behav Dimen Cancer. 2005 Mar;14(3):227-38.

[39] Boman KK, Bodegård G. Life after cancer in childhood: social adjustment and educational and vocational status of young-adult survivors. J Pediatr Hematol Oncol. 2004 Jun 1;26(6):354-62 .
[40] Fong C, Yaghmaian R, Chen X, Wu J-R, Lee B, Iwanaga K et al.. The World Health Organization International Classification of Functioning, Disability and Health as a Framework for Rehabilitation Assessment. In: Strauser DR, Tansey TN, Chan F, editors. New York: Springer Publishing Company. 2019. p. 15-36.

[41] Blustein DL. The role of work in psychological health and well-being: a conceptual, historical, and public policy perspective. American Psychologist. 2008;63(4):228.

[42] Blustein DL. The psychology of working : a new perspective for career development, counseling, and public policy. Counseling and Psychotherapy. Mahwah, N.J.: Lawrence Erlbaum Publishers; 2006.

[43] Neff WS. Work and Human Behavior. New York, NY: Aldine; 1985.

[44] Peterson GW, Sampson Jr JP, Reardon RC. Career development and services: A cognitive approach. University of Virginia: Thomson Brooks/Cole Publishing Co; 1991.

[45] Strauser DR, Greco C, O'Sullivan D. Career and lifestyle planning in vocational rehabilitation settings. In: David C, Mark DS, editors. Career counseling: foundations, perspectives, and applications. 3rd ed. Routledge. 2018.

[46] Strauser DR, O'Sullivan D, Wong AW. Career development and employment of people with disabilities. In: Tarvydas VM, Hartley MT, editors. The Professional practice of rehabilitation counseling New York: Springer; 2018. p.273-96.

[47] Strauser DR, Jones A, Chiu CY, Tansey T, Chan F. Career development of young adult cancer survivors: a conceptual framework. J Vocat Rehabil. 2015 Jan 1;42(2):167-76.

[48] Nissen S, Rumrill P. Employment and career development considerations. In: Giesser B, editor. Primer on multiple sclerosis. 2nd ed. New York: Oxford University Press. 2016:499-514. 